\title{
Pharmaceutical inhibition of AXL suppresses tumor growth and invasion of esophageal squamous cell carcinoma
}

\author{
SHA HAN $^{1 *}$, YEQUAN WANG ${ }^{2 *}$, CHENGYAN GE $^{3}$, MINGTAO GAO $^{3}$, XINTONG WANG $^{3}$, FEIYU WANG $^{3}$, \\ LEI SUN ${ }^{3}$, SHENG LI $^{2}$, TINGTING DONG ${ }^{2}$, ZHEN DANG ${ }^{2}$, WEN CUI ${ }^{2}$, GUOAN ZHANG $^{2}$ and NING LIU ${ }^{4}$ \\ ${ }^{1}$ Collaborative Innovation Center for Birth Defect Research and Transformation of Shandong Province; \\ ${ }^{2}$ Institute of Forensic Medicine and Laboratory Medicine, Forensic Science Center of Jining; \\ ${ }^{3}$ The Second Medical College, Jining Medical University, Jining, Shandong 272067; \\ ${ }^{4}$ Information Technology Centre, Jining Medical University, Jining, Shandong 272067, P.R. China
}

Received February 6, 2020; Accepted July 1, 2020

DOI: $10.3892 /$ etm.2020.9169

\begin{abstract}
Esophageal squamous cell carcinoma (ESCC) is a common type of cancer in a number of regions of the world, including East Asia, South Africa and Iran. It is often associated with poor prognosis rates. Tyrosine-protein kinase receptor UFO (AXL) is overexpressed in a subset of ESCC tumors, therefore the present study aimed to determine the effect of R428, a selective inhibitor of AXL, on ESCC tumor cells. TE1 and KYSE150 cell lines were used as models to investigate the effects of R428 treatment. The proliferative rate of the tumor cells was analyzed using MTT and colony formation assays. In addition, cell migration and invasion rates were analyzed using wound healing and Matrigel assays, respectively. The expression levels of matrix metalloproteinase (MMP)2 and MMP9, and the activation of protein kinase B (AKT), extracellular signal-regulated kinase (ERK) and AXL signaling were analyzed using gelatin zymography and western blotting. The results revealed that R428 inhibited the proliferative and invasive abilities of both cell lines. Furthermore, AXL, AKT and ERK signaling were all decreased in response to R428 treatment, alongside the expression levels of MMP2 and MMP9. In conclusion, the results of the present study suggested that R428 treatment may suppress ESCC tumor cell proliferation and invasion, representing a potential therapeutic target for ESCC.
\end{abstract}

Correspondence to: Mr. Guoan Zhang, Institute of Forensic Medicine and Laboratory Medicine, Forensic Science Center of Jining, Jining Medical University, Laboratory Building, 133 Hehua Road, Jining, Shandong 272067, P.R. China

E-mail: zga2007@126.com

Mr. Ning Liu, Information Technology Centre, Jining Medical University, Laboratory Building, 133 Hehua Road, Jining, Shandong 272067, P.R. China

E-mail: yideyou9@163.com

${ }^{*}$ Contributed equally

Key words: tyrosine-protein kinase receptor UFO, R428, esophageal squamous cell carcinoma, invasion

\section{Introduction}

Esophageal squamous cell carcinoma (ESCC) is a common type of cancer in China and other parts of the world, which is associated with a poor prognosis for the affected patients (1). ESCC is the fourth most common type of cancer in China, accounting for $\sim 375,000$ deaths in 2015 , which represented $\sim 13 \%$ of all cancer-related deaths (2). ESCC is a frequently recurrent cancer with a high mortality rate and an average 5-year survival rate of $>20 \%$ (3), which highlights the importance of discovering novel therapeutic strategies to treat the disease.

Tyrosine-protein kinase receptor UFO (AXL) is a member of the TYRO3, AXL and MERTK (TAM) family of receptor tyrosine kinases (RTKs), which is activated by its ligand, growth arrest-specific protein 6 (GAS6), leading to the activation of several downstream signaling pathways, which is dependent on the cell type, but predominantly includes the PI3K/AKT and mitogen-activated protein kinase (MEK)/ERK signaling pathways. AXL has been previously implicated in the pathophysiology of numerous types of cancer, including breast, gastric, prostate, ovarian and lung cancer (4,5), where it was discovered to promote cancer cell survival, angiogenesis, metastasis and drug-resistance (6-8).

AXL was revealed to be overexpressed in several ESCC tumors, which was associated with an adverse prognosis $(9,10)$ and drug resistance (11). In addition, our previous study demonstrated that AXL was associated with ESCC epithelial-mesenchymal transition (EMT) by analyzing online ESCC gene sets using Gene Set Enrichment Analysis (12). The present study revealed that targeting AXL with R428, the most selective AXL inhibitor currently available (13), suppressed ESCC tumor cell proliferation and invasion through inhibiting matrix metalloproteinase (MMP)2 and MMP9 activity.

\section{Materials and methods}

Cell lines and reagents. TE1 and KYSE150 ESCC cell lines were purchased from The Cell Bank of Type Culture Collection of the Chinese Academy of Sciences. TE1 cells were cultured in RPMI-1640 medium (Gibco; Thermo Fisher 
Scientific, Inc.), supplemented with 10\% FBS (Zhejiang Tianhang Biotechnology Co., Ltd.), whereas KYSE150 cells were cultured in a 1:1 mixture of Ham's F12 medium (Gibco; Thermo Fisher Scientific, Inc.) and RPMI-1640 medium, supplemented with 5\% FBS. Both cell lines were also supplemented with $100 \mathrm{U} / \mathrm{ml}$ penicillin and $0.1 \mathrm{mg} / \mathrm{ml}$ streptomycin (Beyotime Institute of Biotechnology) and maintained in a humidified atmosphere at $37^{\circ} \mathrm{C}$ with $5 \% \mathrm{CO}_{2}$. Cell line authentication was achieved by genetic profiling using the polymorphic short tandem repeat (STR) method at the Forensic Science Center, Jining Medical University (Shandong, China). The results (Table SI) revealed that these cells were identical to the original cells, whereas the STR profile of KYSE150 cells was identical to that reported by $\mathrm{Wu}$ et al (14). R428 was purchased from MedChemExpress and the concentration used was the lowest it could be to suppress the activation of AXL and its downstream signaling pathways $(\leq 5 \mu \mathrm{M}$ in cell proliferation assay and $\leq 3 \mu \mathrm{M}$ in other assays), these concentrations have also been widely used in other studies involving R428 (15-17). The MTT reagent, dimethylformamide (DMF), DMSO and sodium dodecyl sulfate (SDS) were purchased from Sigma-Aldrich (Merck KGaA).

MTT assay. The MTT assay was performed according to the method described by Hansen et al (18). Briefly, $3 \times 10^{3}$ cells/well were plated into 96-well plates and incubated overnight. Subsequently, the cells were treated with R428 or vehicle (DMSO) and incubated for 24,48 or $72 \mathrm{~h}$ at $37^{\circ} \mathrm{C}$. Then, $25 \mu \mathrm{l}$ MTT ( $5 \mathrm{mg} / \mathrm{ml}$ MTT in sterile PBS) was added to the medium and cells were incubated for $2 \mathrm{~h}$ at $37^{\circ} \mathrm{C}$. The reaction was stopped, and the cells were lysed with the addition of $100 \mu \mathrm{l}$ lysis buffer consisting of $20 \%$ SDS in a water/dimethylformamide (1:1) solution ( $\mathrm{pH} 4.7)$. Cell lysates were incubated at $37^{\circ} \mathrm{C}$ overnight to allow for cell lysis and dye solubilization. The absorbance (OD) was measured at 570 and $630 \mathrm{~nm}$, as a reference, using a Multiskan Mk3 microplate reader (Thermo Fisher Scientific, Inc.). The absorbance of each well was calculated as $\mathrm{OD}_{570}-\mathrm{OD}_{630}$. MTT assays were performed in triplicate, with three technical repeats.

Colony formation assay. A total of $1 \times 10^{3}$ cells/well were seeded into six-well plates and incubated overnight. Then, the cells were treated with R428 or vehicle (DMSO) for $24 \mathrm{~h}$ at $37^{\circ} \mathrm{C}$ before the medium was changed to normal growth medium. Following 8 days of incubation for KYSE150 cells, and 14 days for TE1, the cells were washed with PBS twice and stained with crystal violet staining solution at room temperature for $5 \mathrm{~min}$. The number of colonies formed ( $>50$ cells) was counted under a light microscope at $\mathrm{x} 40$ magnification.

Wound healing assay. TE1 and KYSE150 cells were harvested using trypsin and cell suspensions were seeded into six-well plates at a density of $1 \times 10^{6}$ cells/well. Upon the cells reaching $90 \%$ confluence, a $10-\mu 1$ pipette tip was used to scratch a wound on the surface of the cell monolayer. After washing with pre-warmed PBS, the cells were incubated with their respective culture medium containing $1 \%$ FBS and R428 or vehicle (DMSO). Images of the wells were obtained at $0 \mathrm{~h}$, and then again at $14 \mathrm{~h}$ for TE1 cells and $24 \mathrm{~h}$ for KYSE150 cells, in the same position as that at $0 \mathrm{~h}$ under a light microscope at x40 magnification. The images were analyzed using Image J software (version 1.52a; National Institutes of Health) to obtain the area. The migration of cells towards the open gap was determined as the area at $0 \mathrm{~h}$-the area at $14 \mathrm{~h}$ for TE1 cells and the area at $0 \mathrm{~h}$-the area at $24 \mathrm{~h}$ for KYSE150 cells. The assay was performed in triplicate, with three technical repeats. The migratory rate of the control cells was set at $100 \%$ and the migratory rate of the other plates was normalized to the control cells.

Matrigel assay. To investigate cell invasion, $1 \times 10^{6}$ TE1 or KYSE150 cells in normal medium were pretreated with $\mathrm{R} 428$ for $3 \mathrm{~h}$ at $37^{\circ} \mathrm{C}$, then plated into the upper chambers of Transwell plates $(8-\mu \mathrm{m}$ pore size; $6.5 \mathrm{~mm}$ diameter; Corning Life Sciences) precoated with $500 \mu \mathrm{g} / \mathrm{ml}$ Matrigel (Corning Life Sciences) for $1 \mathrm{~h}$ at $37^{\circ} \mathrm{C}$, in medium supplemented with $0.3 \%$ FBS. Medium supplemented with $10 \%$ FBS was plated into the lower chambers. Following incubation for $16 \mathrm{~h}$ (for TE1 cells) or $24 \mathrm{~h}$ (for KYSE150 cells), the invasive cells were fixed with $100 \%$ methanol for $10 \mathrm{~min}$ at room temperature, stained with $0.5 \%$ crystal violet for $30 \mathrm{~min}$ at room temperature and washed with water to remove the excess dye. Stained cells were visualized using an optical microscope under x100 magnification in five randomly selected fields of view. The invasive rate of the control cells was set at $100 \%$ and the invasive rate of the other groups was normalized to the control cells.

Western blotting. Western blotting was performed as previously described (19). Briefly, total cellular protein was extracted from cells using RIPA lysis buffer containing protease inhibitors and phosphatase inhibitors. Extracted protein (20 $\mu \mathrm{g}$ per lane) was separated via $10 \%$ SDS-PAGE and transferred onto PVDF membranes. The membrane was blocked for $1 \mathrm{~h}$ in $5 \%$ non-fat milk solution at room temperature and then incubated with the indicated primary antibodies overnight at $4^{\circ} \mathrm{C}$. Following the primary antibody incubation, the membranes were incubated with horseradish peroxidase-conjugated secondary antibodies at room temperature for $1 \mathrm{~h}$. Protein bands were visualized using an ECL reagent (cat. no. CW0049; CoWin Biosciences). GAPDH was used as the endogenous loading control. Anti-AXL (cat. no. 8661; 1:1,000), anti-phosphorylated (p)-AKT (cat. no. 4060; 1:1,000) and anti-AKT (cat. no. 4691; 1:1,000) primary antibodies were purchased from Cell Signaling Technology, Inc. The anti-p-AXL antibody (cat. no. AF2228; 1:200) was obtained from R\&D Systems China Co., Ltd. Anti-GAPDH antibody (Clone OT12DG; cat. no. TA-08; 1:1,000) was purchased from OriGene Technologies, Inc. Anti-ERK1+ERK2 (cat. no. ab184699; 1:10,000) and anti-p-ERK1+ERK2 (cat. no. ab76299; 1:10,000) primary antibodies were purchased from Abcam.

Gelatin zymography to determine the activity of MMP2 and MMP9. MMP2 and MMP9 activity from the collected samples was assayed using $0.05 \%$ gelatin zymography, as previously described (20). Briefly, $5 \times 10^{5}$ cells were cultured in six-well plates overnight, and then R428 was added to the medium and incubated for $24 \mathrm{~h}$ at $37^{\circ} \mathrm{C}$. Following incubation, the medium was changed to $700 \mu 1$ serum-free medium containing R428. Following incubation for $18 \mathrm{~h}$, the medium 
was collected for analysis. The protein concentration of each sample was measured using a bicinchoninic acid protein assay kit (cat. no. P0010; Beyotime Institute of Biotechnology) and equal amounts of total protein were separated via $10 \%$ SDS-PAGE gels co-polymerized with $0.05 \%$ gelatin. After electrophoresis, the gels were washed in $2.5 \%$ Triton X-100 three times for $1.5 \mathrm{~h}$ at room temperature to remove the SDS and regain activity. The washed gels were then bathed in proteolysis buffer $\left(50 \mathrm{mM} \mathrm{CaCl} \mathrm{m}_{2}, 0.5 \mathrm{M} \mathrm{NaCl}, 50 \mathrm{mM}\right.$ Tris; $\mathrm{pH}$ 7.8) and incubated at $37^{\circ} \mathrm{C}$ for $15 \mathrm{~h}$. Following incubation, the gels were rinsed in $2.5 \%$ Triton $\mathrm{X}-100$ solution and stained at room temperature with Coomassie blue (45\% methanol, $44.75 \% \mathrm{H}_{2} \mathrm{O}, 10 \%$ acetic acid, $0.25 \%$ Coomassie blue R-250) for $1 \mathrm{~h}$ on a rotator. Gels were de-stained with a solution containing $40 \%$ methanol, $7.5 \%$ acetic acid and $52.5 \% \mathrm{H}_{2} \mathrm{O}$ for a few hours until the bands became clear. The gelatin inside the gel bound to the Coomassie blue, dyeing the gel blue and leaving the MMP-digested regions white in color. Bands were scanned using a Bio-Rad ChemiDoc ${ }^{\mathrm{TM}}$ imager (Bio-Rad Laboratories, Inc.).

Reverse transcription-quantitative PCR (RT-qPCR). Total RNA was extracted from cells using TRIzol reagent (Invitrogen; Thermo Fisher Scientific, Inc.), according to the manufacturer's protocol. First-strand cDNA was synthesized from $0.5 \mu \mathrm{g}$ RNA using a PrimeScript ${ }^{\mathrm{TM}}$ RT Master mix (cat. no. RR036A, Takara Biotechnology Co., Ltd.), by incubation at $37^{\circ} \mathrm{C}$ for $15 \mathrm{~min}$ and then $85^{\circ} \mathrm{C}$ for $5 \mathrm{sec}$, according to the manufacturer's instructions. qPCR was subsequently performed in triplicate using the SYBR Green PCR Master mix (CoWin Biosciences) on a QuantStudio ${ }^{\mathrm{TM}} 5$ Real-Time PCR system (Thermo Fisher Scientific, Inc.). The following primer pairs were used: MMP2 forward, 5'-TACAGGATCATT GGCTACACACC-3' and reverse, 5'-GGTCACATCGCTCCA GACT-3'; MMP9 forward, 5'-GGGACGCAGACATCGTCA TC-3' and reverse, 5'-TCGTCATCGTCGAAATGGGC-3'; and GAPDH forward, 5'-GGAGCGAGATCCCTCCAAAAT-3' and reverse, 5'-GGCTGTTGTCATACTTCTCATGG-3'. Each qPCR reaction was performed in a final volume of $20 \mu \mathrm{l}$, containing $10 \mu \mathrm{l} \mathrm{SYBR}$ Green Master mix (2X), $0.5 \mu \mathrm{l}$ forward and reverse primers $(10 \mu \mathrm{M}), 8 \mu \mathrm{l}$ DEPC treated water and $1 \mu \mathrm{l}$ cDNA. The following thermocycling conditions were used for the qPCR: $95^{\circ} \mathrm{C}$ for $10 \mathrm{~min}, 40$ cycles of $95^{\circ} \mathrm{C}$ for $15 \mathrm{sec}$ and $60^{\circ} \mathrm{C}$ for $1 \mathrm{~min}$. Data were normalized to GAPDH expression levels, the housekeeping gene. The relative expression of target genes was calculated by the comparative $2^{-\Delta \Delta \mathrm{Cq}}$ method (21).

Statistical analysis. Statistical differences between experimental and control groups were analyzed using an unpaired two-tailed Student's t-test (2 groups) or a one-way ANOVA (>2 groups) followed by a multiple post hoc comparisions test (Dunnett's test) using GraphPad Prism 8 software (GraphPad Software, Inc.). $\mathrm{P}<0.05$ was considered to indicate a statistically significant difference.

\section{Results}

AXL is activated in ESCC cells and R428 suppresses AXL activation. To determine the effect of R428 on ESCC tumor cells, the expression levels of AXL in TE1 and KYSE150 cells

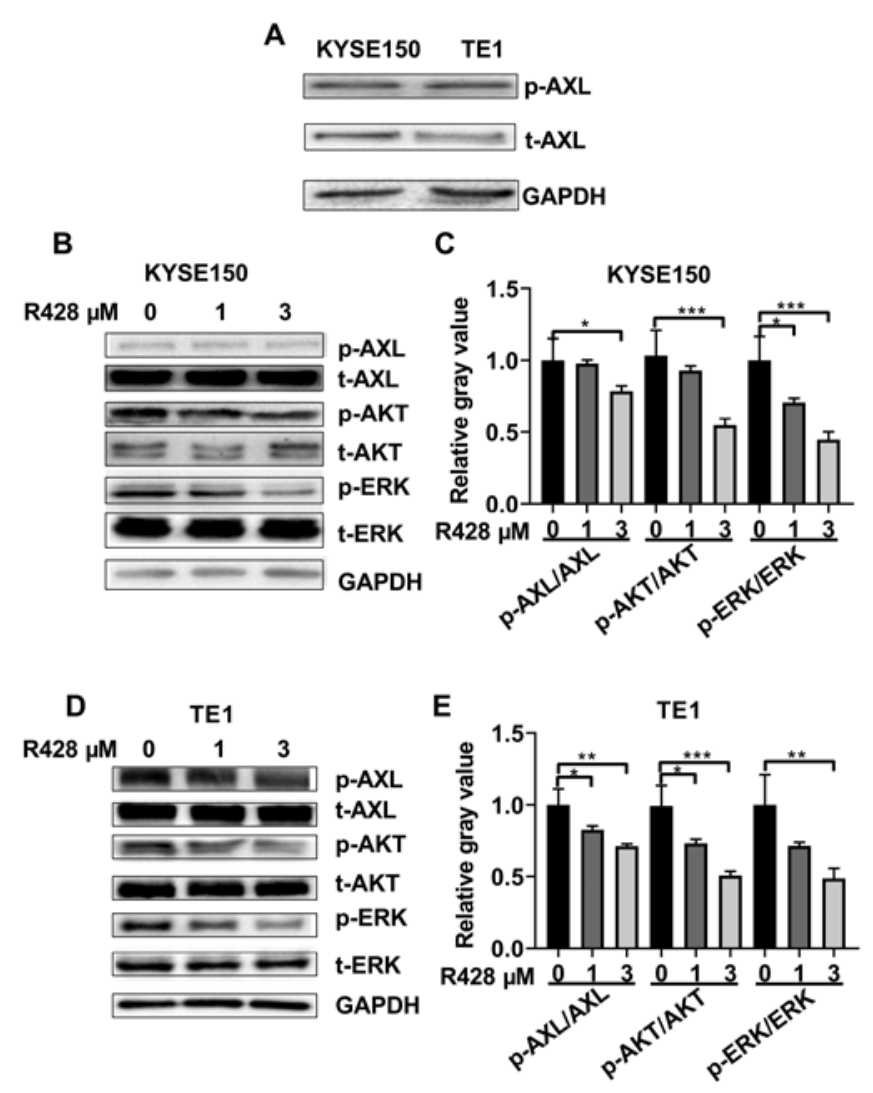

Figure 1. R428 suppresses the activation of AXL in esophageal squamous cell carcinoma cells. (A) Expression levels of t-AXL and p-AXL in KYSE150 and TE1 cells. (B) R428 treatment inhibited AXL activation, in addition to AKT and ERK activation, in a dose-dependent manner in KYSE150 cells. (C) Semi-quantitative analysis of the expression levels of p-AXL, p-AKT and p-ERK. (D) R428 inhibited AXL activation, in addition to AKT and ERK activation in a dose-dependent manner in TE1 cells. (E) Semi-quantitative analysis of the expression levels of p-AXL, p-AKT and p-ERK. ${ }^{*} \mathrm{P}<0.05$, ${ }^{* *} \mathrm{P}<0.01,{ }^{* * *} \mathrm{P}<0.001$. AXL, tyrosine-protein kinase receptor UFO; t, total; p, phosphorylated.

were determined using western blotting. Both cell lines were found to express AXL and activated AXL (AXL phosphorylated at tyrosine residue 779; Fig. 1A). It was also confirmed that R428 treatment suppressed AXL activation in both TE1 and KYSE150 cells in a dose-dependent manner (Fig. 1B-E). AKT and ERK signaling are two major branches of AXL signaling $(4,22,23)$, thus their responses to R428 were determined; it was identified that R428 treatment suppressed AKT and ERK signaling activation in a dose-dependent manner (Fig. 1B-E).

R428 treatment reduces cell proliferation in ESCC cells in vitro. The effects of R428 treatment on cell proliferation were subsequently investigated. The results of the MTT assay revealed that $\mathrm{R} 428$ treatment reduced cell viability in a timeand dose-dependent manner in both cell lines (Fig. 2A and B). Furthermore, the colony formation assay demonstrated that R428 treatment suppressed cell colony formation in a dose-dependent manner (Fig. 2C and D), suggesting that AXL signaling may enhance ESCC proliferation.

R428 treatment inhibits ESCC cell migration and invasion. The effects of R428 treatment on ESCC cell migration and 
A

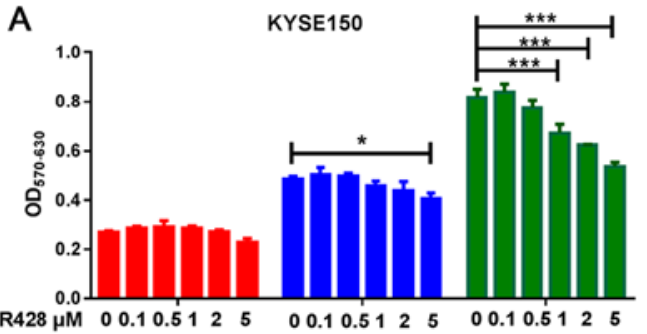

$24 \mathrm{~h}$

c

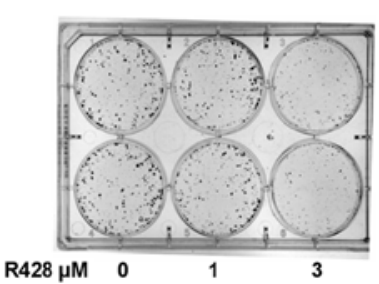

$48 \mathrm{~h}$

$72 \mathrm{~h}$

KYSE150

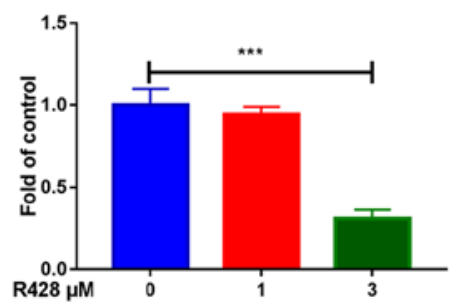

B

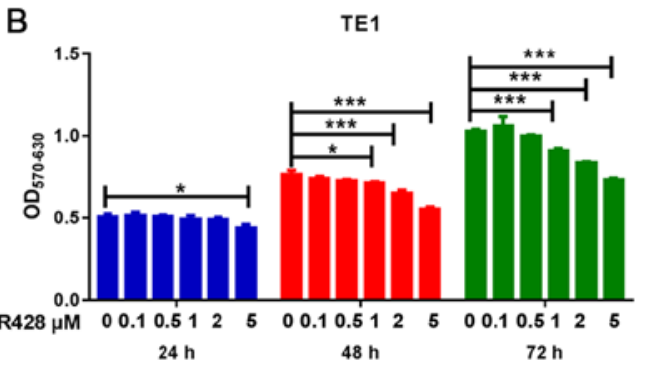

D

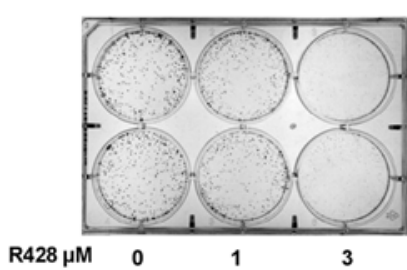

TE1

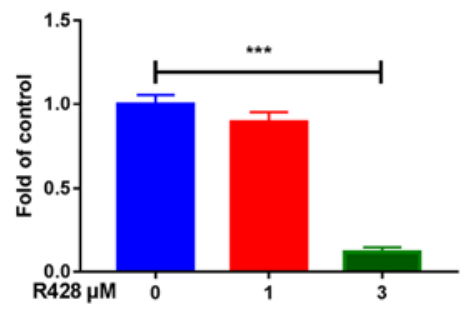

Figure 2. R428 reduces cell proliferation in esophageal squamous cell carcinoma cells. (A) KYSE150 and (B) TE1 cells were treated with R428 at the indicated concentration for 24, 48 and $72 \mathrm{~h}$, and the viability was determined using an MTT assay. Cell proliferation in response to R428 was determined using a colony formation assay in (C) KYSE150 and (D) TE1 cells. ${ }^{*} \mathrm{P}<0.05,{ }^{* * *} \mathrm{P}<0.001$.

A

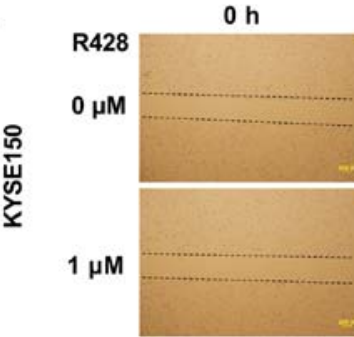

B

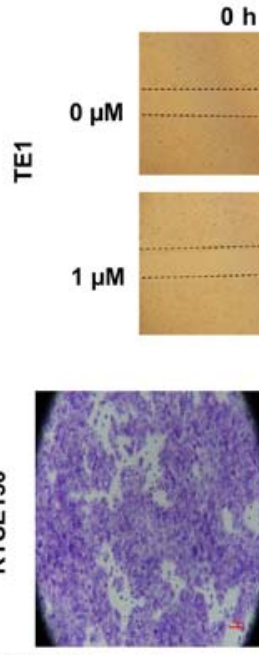

R428 $\mu \mathrm{M}$

D

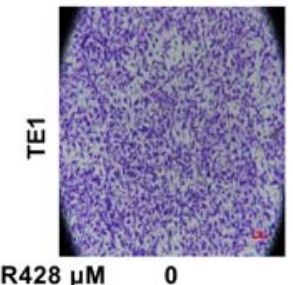

$\mathrm{oh}$

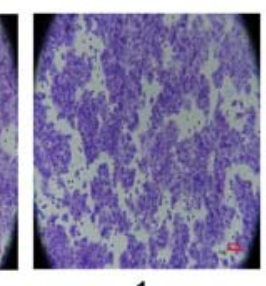

1

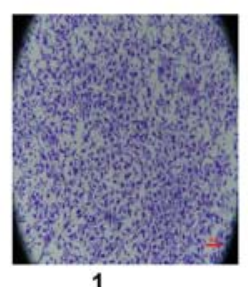

$14 \mathrm{~h}$
$24 \mathrm{~h}$
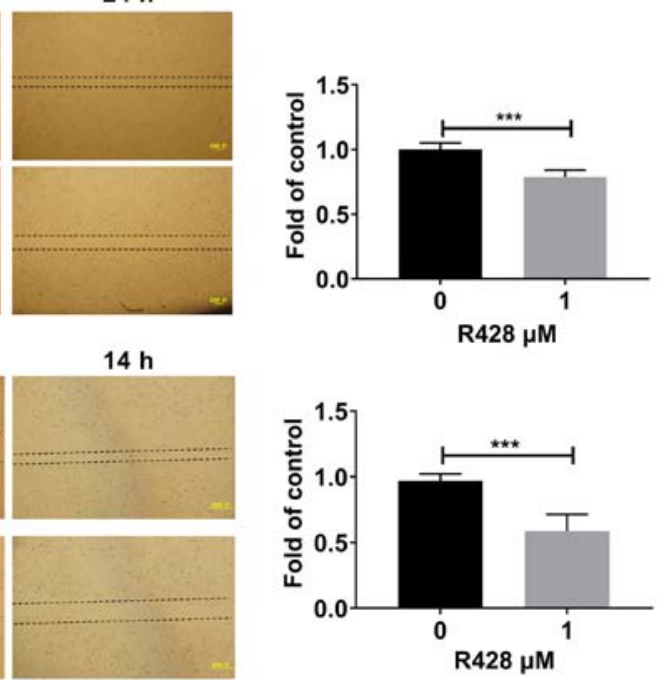

$\mathrm{R} 428 \mu \mathrm{M}$
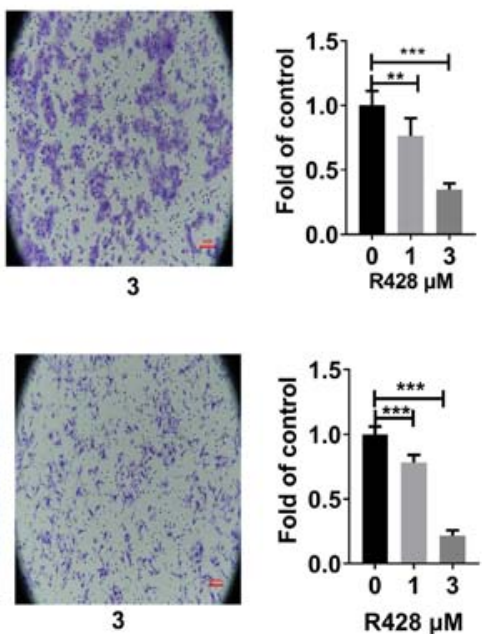

Figure 3. R428 suppresses invasion and migration of esophageal squamous cell carcinoma cells. Wound healing assay revealed that the migratory abilities of (A) KYSE150 and (B) TE1 cells were reduced following treatment with $1 \mu \mathrm{M}$ R428. The Matrigel assay revealed that the invasive abilities of (C) KYSE150 and (D) TE1 cells were reduced by $\mathrm{R} 428$ treatment. ${ }^{*} \mathrm{P}<0.05,{ }^{* * *} \mathrm{P}<0.001$. 

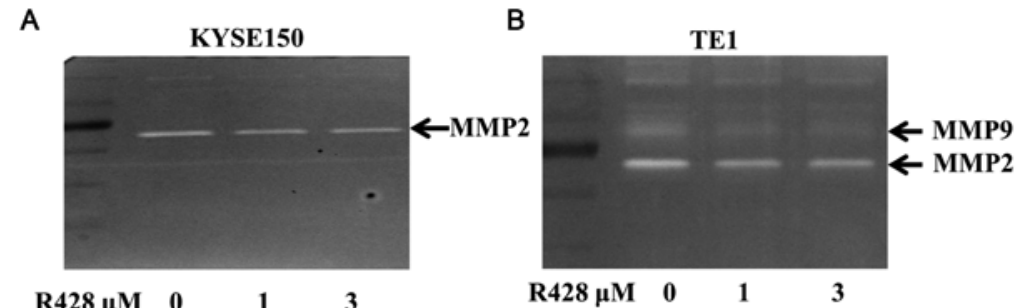

$\mathrm{C}$

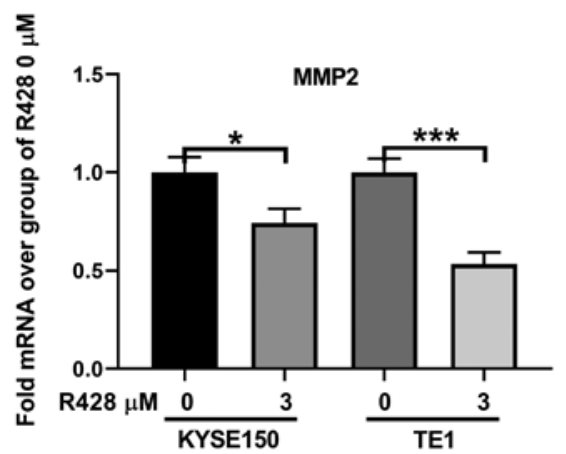

D

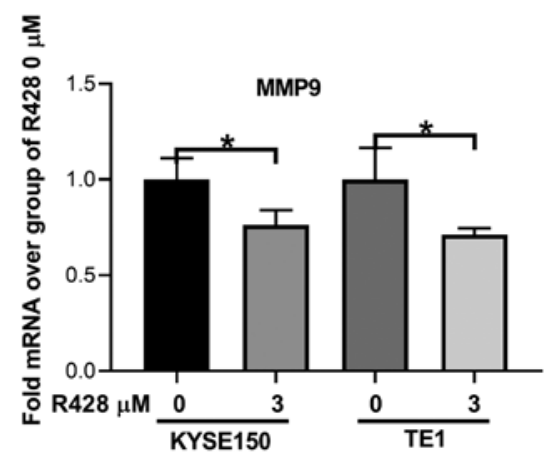

Figure 4. R428 reduces the expression of MMP2 and MMP9. MMP2 and MMP9 expression levels were downregulated by R428 treatment in (A) KYSE150 and (B) TE1 cells, as determined by gelatin zymography. (C) MMP2 and (D) MMP9 mRNA expression levels in KYSE150 and TE1 cells were determined by reverse transcription-quantitative PCR. ${ }^{*} \mathrm{P}<0.05,{ }^{* * * *} \mathrm{P}<0.001$. MMP, matrix metalloproteinase.

invasion were subsequently investigated. The results of the wound healing assay revealed that R428 treatment inhibited the migration of both KYSE150 and TE1 cells (Fig. 3A and B). In addition, the Matrigel assay also demonstrated that both 1 and $3 \mu \mathrm{M}$ R428 treatment suppressed tumor cell invasion (Fig. 3C and D). These results suggested that R428 treatment may significantly inhibit tumor migration and invasion.

R428 treatment downregulates MMP2 and MMP9 expression levels. MMP2 and MMP9 are important regulators of tumor invasion, and both have been previously revealed to be involved in AXL-mediated tumor cell invasion (24-27). Thus, the present study aimed to determine whether MMP2 and MMP9 were also involved in the R428-induced suppression of ESCC invasion. Gelatin zymography demonstrated that R428 treatment suppressed both MMP2 and MMP9 activity in TE1 cells. In KYSE150 cells, MMP2 activity was also inhibited, whereas MMP9 activity was not detected (Fig. 4A and B). Furthermore, the mRNA expression levels of MMP2 and MMP9 were analyzed in both cell lines; R428 treatment downregulated the expression levels of both MMP2 and MMP9 (Fig. 4C and D).

\section{Discussion}

ESCC is a cancer with high mortality rates, for which no targeted therapies have been approved. R428 treatment is currently under phase I or II clinical trials in several types of cancer (28). Previous immunohistochemistry studies have revealed that AXL was overexpressed in ESCC tumors $(9,10)$. Thus, the aim of the present study was to investigate the effect of R428 treatment on ESCC cancer cells in vitro.

The present study revealed that the two ESCC cell lines, KYSE150 and TE1, expressed AXL in the activated form. AXL can be activated by its ligand GAS6 or by other molecules via atypical activation $(23,29)$. For example, epidermal growth factor (EGF), which activates the EGF receptor, was discovered to subsequently transactivate AXL (17). In addition, hepatocyte growth factor (HGF) was reported to activate AXL by promoting the formation of HGF receptor MET and AXL complexes (30). However, the pathway involved in the activation of AXL in the two cell lines requires further investigations. AXL has been elucidated to be involved in the proliferation of cancer cells $(4,16,31,32)$. Consistent with these results, the present study also revealed that R428 treatment suppressed ESCC proliferation. Of note, Hsieh et al (9) revealed that ESCC cells were more sensitive to the AXL inhibitor foretinib compared with the HER2 inhibitor lapatinib, suggesting that AXL seems a better target in the treatment of ESCC than HER2.

Patients with solid tumors primarily succumb to mortality due to metastatic lesions, rather than from the primary tumor (33). AXL has been identified to be highly associated with cancer EMT and invasion (22). Our previous study also revealed that ESCC tumors expressing high levels of AXL displayed enhanced EMT properties and the invasive ESCC cells expressed increased levels of AXL (12). Thus, it is not surprising that targeting AXL with R428 suppressed ESCC cancer cell migration and invasion in the present study, which is also consistent with the study of Yang et al (16). However, in the wound healing assay $1 \%$ FBS was used, which may be a limitation. Mechanistically, MMP9 and MMP2 have been reported to mediate, at least partially, the effect of AXL on cell invasion. In previous studies, AXL was discovered to upregulate the expression levels of MMP9 and MMP2 (24-27), which promoted tissue remodeling and cancer invasion. The present study confirmed the association between MMP2, MMP9 and AXL by observing that R428 decreased the expression of MMP2 and MMP9. MMP9 was detected by 
real-time PCR, but not detected by gelatin zymography in KYSE150 cells, this may be because gelatin zymography is not a sensitive enough technique for the detection of MMPs. It would be useful to study whether GAS6, the ligand of AXL, could promote the proliferation and invasion of ESCC, and whether R428 could suppress the effects of GAS6, which will further confirm the role of AXL in ESCC progression. However, these experiments were not performed, which is a limitation in the present study.

In conclusion, ESCC is a common type of cancer with a poor prognosis, of which there are currently no targeted therapies approved for the treatment of this disease. The findings of the present study suggested that R428 treatment may suppress ESCC tumor cell proliferation and invasion, therefore representing a potential therapeutic strategy for the treatment of ESCC.

\section{Acknowledgements}

Not applicable.

\section{Funding}

This study was supported by innovation and entrepreneurship training program for college students of Jining Medical University (grant nos. cx2016034 and cx2019014); Supporting Fund for Teachers' Research of Jining Medical University (grant nos. JY2017KJ040 and JYFC2018KJ010); Research Fund for Lin He's Academician Workstation of New Medicine and Clinical Translation in Jining Medical University (grant nos. JYHL2018MS13 and JYHL2018MS14); Jining Science and Technology Boost the Old and New Kinetic Energy Conversion Project (grant no. 2018SMNS001), and Shandong Provincial Natural Science Foundation (grant no. ZR2019PH039).

\section{Availability of data and materials}

The datasets used and/or analyzed during the present study are available from the corresponding author on reasonable request.

\section{Authors' contributions}

GZ, WC and NL designed the study. SH, YW, CG, MG, XW, FW and LS performed the experiments. SL, TD and ZD analyzed the data. GZ and NL prepared the manuscript. All authors read and reviewed the final manuscript.

\section{Ethics approval and consent to participate}

Not applicable.

\section{Patient consent for publication}

Not applicable.

\section{Competing interests}

The authors declare that they have no competing interests.

\section{References}

1. Jemal A, Bray F, Center MM, Ferlay J, Ward E and Forman D: Global cancer statistics. CA Cancer J Clin 61: 69-90, 2011.

2. Chen W, Zheng R, Baade PD, Zhang S, Zeng H, Bray F, Jemal A, Yu XQ and He J: Cancer statistics in China, 2015. CA Cancer J Clin 66: 115-132, 2016.

3. Allum WH, Stenning SP, Bancewicz J, Clark PI and Langley RE: Long-term results of a randomized trial of surgery with or without preoperative chemotherapy in esophageal cancer. J Clin Oncol 27: 5062-5067, 2009.

4. Paccez JD, Vogelsang M, Parker MI and Zerbini LF: The receptor tyrosine kinase Axl in cancer: Biological functions and therapeutic implications. Int J Cancer 134: 1024-1033, 2014.

5. Qu X, Liu G, Zhong X, Li X and Zhang Q: Role of AXL expression in non-small cell lung cancer. Oncol Lett 12: 5085-5091, 2016.

6. Graham DK, DeRyckere D, Davies KD and Earp HS: The TAM family: Phosphatidylserine sensing receptor tyrosine kinases gone awry in cancer. Nat Rev Cancer 14: 769-785, 2014.

7. Zhang Z, Lee JC, Lin L, Olivas V, Au V, LaFramboise T, Abdel-Rahman M, Wang X, Levine AD, Rho JK, et al: Activation of the AXL kinase causes resistance to EGFR-targeted therapy in lung cancer. Nat Genet 44: 852-860, 2012.

8. Duan Y, Hu B, Qiao C, Luo L, Li X, Wang J, Liu H, Zhou T, Shen B, Lv M and Feng J: Engineered AXL-ECD-Fc variants that abolish the AXL/Gas6 interaction suppress tumor cell migration. Oncol Lett 17: 5784-5792, 2019.

9. Hsieh MS, Yang PW, Wong LF and Lee JM: The AXL receptor tyrosine kinase is associated with adverse prognosis and distant metastasis in esophageal squamous cell carcinoma. Oncotarget 7: 36956-36970, 2016.

10. Paccez JD, Duncan K, Vava A, Correa RG, Libermann TA, Parker MI and Zerbini LF: Inactivation of GSK3 $\beta$ and activation of NF- $\kappa$ B pathway via Axl represents an important mediator of tumorigenesis in esophageal squamous cell carcinoma. Mol Biol Cell 26: 821-831, 2015.

11. Elkabets M, Pazarentzos E, Juric D, Sheng Q, Pelossof RA, Brook S, Benzaken AO, Rodon J, Morse N, Yan JJ, et al: AXL mediates resistance to $\mathrm{PI} 3 \mathrm{~K} \alpha$ inhibition by activating the EGFR/PKC/mTOR Axis in head and neck and esophageal squamous cell carcinomas. Cancer Cell 27: 533-546, 2015.

12. Zhang G, Kong X, Wang M, et al: AXL is a marker for epithelialmesenchymal transition in esophageal squamous cell carcinoma. Oncol Lett 15: 1900-1906, 2018.

13. Myers SH, Brunton VG and Unciti-Broceta A: AXL inhibitors in cancer: A medicinal chemistry perspective. J Med Chem 59: 3593-3608, 2016.

14. Wu Y, Hu L, Liang Y, Li J, Wang K, Chen X, Meng H, Guan X, Yang $\mathrm{K}$ and Bai Y: Up-regulation of IncRNA CASC9 promotes esophageal squamous cell carcinoma growth by negatively regulating PDCD4 expression through EZH2. Mol Cancer 16: 150, 2017.

15. Holland SJ, Pan A, Franci C, Hu Y, Chang B, Li W, Duan M, Torneros A, Yu J, Heckrodt TJ, et al: R428, a selective small molecule inhibitor of Axl kinase, blocks tumor spread and prolongs survival in models of metastatic breast cancer. Cancer Res 70: 1544-1554, 2010.

16. Yang PW, Liu YC, Chang YH, Lin CC, Huang PM, Hua KT, Lee JM and Hsieh MS: Cabozantinib (XL184) and R428 (BGB324) inhibit the growth of esophageal squamous cell carcinoma (ESCC). Front Oncol 9: 1138, 2019.

17. Meyer AS, Miller MA, Gertler FB and Lauffenburger DA: The receptor AXL diversifies EGFR signaling and limits the response to EGFR-targeted inhibitors in Triple-negative breast cancer cells. Sci Signal 6: ra66, 2013.

18. Hansen MB, Nielsen SE and Berg K: Re-examination and further development of a precise and rapid dye method for measuring cell growth/cell kill. J Immunol Methods 119: 203-210, 1989.

19. Kong LL, Man DM, Wang T, Zhang GA and Cui W: siRNA targeting RBP2 inhibits expression, proliferation, tumorigenicity and invasion in thyroid carcinoma cells. Oncol Lett 10: 3393-3398, 2015.

20. Tang Z, Yang L, Wang Y, Xue R, Zhang J, Huang W, Chen PC and Sung KL: Contributions of different intraarticular tissues to the acute phase elevation of synovial fluid MMP-2 following rat ACL rupture. J Orthop Res 27: 243-248, 2009.

21. Livak KJ and Schmittgen TD: Analysis of relative gene expression data using real-time quantitative PCR and the 2(-Delta Delta C(T)) method. Methods 25: 402-408, 2001. 
22. Antony $\mathbf{J}$ and Huang RY: AXL-Driven EMT state as a targetable conduit in cancer. Cancer Res 77: 3725-3732, 2017.

23. Zhang G, Wang M, Zhao $\mathrm{H}$ and Cui W: Function of Axl receptor tyrosine kinase in non-small cell lung cancer. Oncol Lett 15: 2726-2734, 2018.

24. Tai KY, Shieh YS, Lee CS, Shiah SG and Wu CW: Axl promotes cell invasion by inducing MMP-9 activity through activation of NF-kappaB and Brg-1. Oncogene 27: 4044-4055, 2008.

25. Reichl P, Dengler M, van Zijl F, Huber H, Führlinger G, Reichel C, Sieghart W, Peck-Radosavljevic M, Grubinger M and Mikulits W: Axl activates autocrine transforming growth factor- $\beta$ signaling in hepatocellular carcinoma. Hepatology 61: 930-941, 2015.

26. Chiu KC, Lee CH, Liu SY, Yeh CT, Huang RY, Yuh DY Cheng JC, Chou YT and Shieh YS: Protumoral effect of macrophage through Axl activation on mucoepidermoid carcinoma. J Oral Pathol Med 43: 538-544, 2014.

27. Han J, Tian R, Yong B, Luo C, Tan P, Shen J and Peng T: Gas6/Axl mediates tumor cell apoptosis, migration and invasion and predicts the clinical outcome of osteosarcoma patients. Biochem Biophys Res Commun 435: 493-500, 2013.

28. Wu G, Ma Z, Hu W, Wang D, Gong B, Fan C, Jiang S, Li T, Gao J and Yang Y: Molecular insights of Gas6/TAM in cancer development and therapy. Cell Death Dis 8: e2700, 2017.
29. Linger RM, Keating AK, Earp HS and Graham DK: TAM receptor tyrosine kinases: Biologic functions, signaling, and potential therapeutic targeting in human cancer. Adv Cancer Res 100: 35-83, 2008

30. Zhang G, Wang M, Zhao $\mathrm{H}$ and Cui W: Function of Axl receptor tyrosine kinase in non-small cell lung cancer. Oncol Lett 15: 2726-2734, 2018

31. Verma A, Warner SL, Vankayalapati H, Bearss DJ and Sharma S: Targeting Axl and Mer kinases in cancer. Mol Cancer Ther 10: 1763-1773, 2011.

32. Scaltriti M, Elkabets M and Baselga J: Molecular pathways: AXL, a membrane receptor mediator of resistance to therapy. Clin Cancer Res 22: 1313-1317, 2016.

33. Hanahan D and Weinberg RA: The hallmarks of cancer. Cell 100: 57-70, 2000.

(i) (9) This work is licensed under a Creative Commons Attribution-NonCommercial-NoDerivatives 4.0 International (CC BY-NC-ND 4.0) License. 